\title{
Role of Early Childhood Traumatic Stress in the Development of PTSD in Adulthood: A Review
}

Mansoor Ahmad Dar ${ }^{1 *}$, Rayees Ahmad Wani ${ }^{1}$, Mushtaq Ahmad Margoob ${ }^{1}$, Inaamul Haq ${ }^{2}$, Rajesh Kumar Chandel ${ }^{1}$, Arshad Hussain ${ }^{1}$, Khurshid Ahmad Bhat ${ }^{3}$, Irfan Ahmad Shah ${ }^{4}$, Yasir Hassan Rather ${ }^{1}$, Majid Shafi Shah ${ }^{1}$, Altaf Ahmad Malla ${ }^{1}$ and Bilal Ahmad Bhat ${ }^{1}$

${ }^{1}$ Department of Psychiatry, Government Medical College, Srinagar, Jammu and Kashmir, India

${ }^{2}$ Department of Community Medicine, Government Medical College, Srinagar, Jammu and Kashmir, India

${ }^{3}$ Department of Orthopaedics, Government Medical College, Jammu, Jammu and Kashmir, India

${ }^{4}$ Department of Neurology, Sher-e-Kashmir Institute of Medical Sciences, Srinagar, Jammu and Kashmir, India

\begin{abstract}
Traumatic stress has been known through ages and children make a significant group to face it. Vast research has been done in traumatic stress to show the cause effect relationship. Post-traumatic stress disorder (PTSD) has been recognized subsequent to trauma and has been invariably linked to it. Besides PTSD, there have been a multitude of psychopathologies attributed to childhood traumas. Short-term effects of childhood traumas are studied in depth but the long-term effects are subject to a variety of risk and protective factors. Childhood maltreatment and other cumulative traumas are shown to cause a spectrum of anxiety disorders and mood disorders besides others; in contrast to single traumas of childhood mainly presenting as PTSD as a pathology. Re-trauma in adulthood of these early traumatized children seems to be a risk factor for PTSD and other pathologies. Significant neurobiological changes (structural and genetic) have been shown to occur in adults with childhood traumatic experiences. Resilience has been significant and has been seen more developed in children with effective parenting, stable families, adequate social support, spirituality and humour. Positive self-esteem, ego flexibility, and ego over-control are protective. These protective practices need to be identified and promoted in children with special emphasis in those having experienced traumatic stress.
\end{abstract}

Keywords: Trauma; Children; Post-traumatic stress disorder; Depression; Effects

\section{Introduction}

A long traditional debate has been going on regarding the mental health effects of trauma in psychiatry. Pathological stress response syndromes have been known to result from exposure to war, sexual assault and other types of trauma. Evidence for post-traumatic reactions date back as far as the Sixth century B.C.; early documentation typically involved the reactions of soldiers in combat. Beginning in the 17thcentury, anecdotal evidence of trauma exposure and subsequent responses were more frequently reported. In 1666, Samuel Pepys wrote about individual's responses to the Great Fire of London [1-3].

In the context of current turmoil prevalent worldwide, no age group is immune from exposure to trauma, and its consequences [4]. The National Co morbidity Survey in America estimated the lifetime exposure to any trauma among men and women at $60.7 \%$ and $51.2 \%$ respectively [1]. Similarly, the Australian National Mental Health Survey reported the lifetime exposure to trauma among men and women at $64.6 \%$ and $49.5 \%$ respectively [5]. Lesser epidemiological studies on trauma in general populations have emerged from poor and economically developing countries, although some recent research has began to improve our understanding of trauma in poor, war torn countries [6-8].

The association between retrospectively reported childhood adverse experiences/traumas and psychiatric morbidity in adulthood is documented in several surveys of community and clinical samples $[9,10]$. Research studies in recent years have confirmed that PTSD and its inherent co-morbidity occurs not only in adult victims of traumatic life events but in children across the age spectrum [11]. However it has been difficult to substantiate this causal link with the prospective longitudinal data, but, the assumption remains viable based mostly on cross sectional and/or retrospective studies of persons with psychopathology, and in particular PTSD, who report such early life trauma. This paper reviews the effects of childhood trauma in the form of PTSD besides discussing the basic concept of childhood trauma. It will also discuss variation in symptom presentation of single and cumulative trauma vis-a-vis development of PTSD. Neurobiology of trauma and the protective factors will also be reviewed.

\section{Childhood Traumas and PTSD: Cumulative Versus Single Traumatic Stressors}

Since children form 40 percent of the total population in developing countries, and 25 percent of population in developed countries, the recognition of psychiatric problems in children by adults is important, as it is they who determine whether and where consultation and treatment will be sought. Historically childhood studies of trauma expanded from clinical case reports to systematic comparisons using a 'dose of exposure' design with inclusions of contemporaneous, comparison and control groups. There has been continuous controversy about the impact of disasters/traumas on victims including children and some investigators denied that serious psychological effects occurred, however this denial was based on inadequate extremely narrow research conducted by clinicians and has called for more systematic, clinically relevant investigations [12-16].

*Corresponding author: Mansoor Ahmad Dar, Senior Resident, Department of Psychiatry, Government Medical College, Srinagar, Jammu and Kashmir, India, 190003, Tel: 009596010111; E-mail: gaashmansoor@gmail.com

Received October 10, 2014; Accepted February 27, 2015; Published March 08 , 2015

Citation: Dar MA, Wani RA, Margoob MA, Haq I, Chandel RK et al., (2015) Role of Early Childhood Traumatic Stress in the Development of PTSD in Adulthood: A Review. J Psychiatry 18: 264 doi: 10.4172/2378-5756.1000264

Copyright: (C) 2015 Dar MA, et al. This is an open-access article distributed under the terms of the Creative Commons Attribution License, which permits unrestricted use, distribution, and reproduction in any medium, provided the original author and source are credited 
Although nowadays nearly every researcher agrees that early childhood traumas lie at the root of most long-term depression and anxiety, and many emotional and psychological illnesses. But among mental health professionals, and even among some childhood development specialists, there is sometimes a lack of understanding over exactly what constitutes childhood abuse. A seminal American Academy of Paediatrics (AAP) report 1995 defines childhood abuse as "a repeated pattern of damaging interactions between parent(s) [or, presumably, other significant adults] and child that becomes typical of the relationship." In addition to physical, sexual and verbal abuse, this can include anything that causes the child to feel worthless, unlovable, insecure, and even endangered, or as if his only value lies in meeting someone else's needs. Examples cited in the report include "belittling, degrading or ridiculing a child; making him or her feel unsafe [including threat of abandonment]; failing to express affection, caring and love; neglecting mental health, medical or educational needs." The AAP also includes parental divorce in the list of potentially harmful events which can traumatize a child $[17,18]$.

Early maltreatment and other cumulative traumas are related to adult PTSD as higher rates of childhood abuse and maltreatment have been found among individuals with PTSD than among those without PTSD $[19,20]$. But cumulative traumas have more often been shown to be associated with higher rates of anxiety, suicidality, dissociation, personality disorders, substance abuse, physical illness, and interpersonal problems [21-25]. Slow trauma in the form of adverse parental rearing styles (including lack of care and overprotection) has been associated with the risk for anxiety disorders [10]. Altogether there is a growing evidence for the pervasiveness of cumulative exposure to violence/maltreatment/abuse as contrasted to exposure to a single discrete episode of trauma led Finkelhor et al. to postulate that victimization is a "condition" rather than an "event." Cross-sectional studies have indicated that among children who experience war trauma, between $25 \%$ and $62 \%$ suffer from PTSD [26-29].

Single traumas have a different effect than the cumulative traumas. Up to $87 \%$ of children have been shown to suffer from PTSD after traumas of natural disasters [30-32]. Very high rates of PTSD have been seen to occur after traumas of extreme violence; for example, the rates of PTSD after being kidnapped, witnessing the murder of a parent, or experiencing violence have ranged from $95 \%$ to $100 \%[33,34]$.

The review of the present evidences has shown that, there is a higher rate of PTSD in children in response to single-episode childhood trauma, although the majority may recover within a relatively short period of time. The studies have also suggested that childhood maltreatment itself is not commonly related to adult PTSD and other factors need to be considered in understanding the association between childhood abuse and adult PTSD. Rather childhood maltreatment and abuse has been shown to give rise to other anxiety disorders and the single traumas have more propensities to lead to acute PTSD [35].

\section{Early Life Trauma and PTSD: Effects of Adulthood Traumas}

Time and again early life trauma has been demonstrated to be a risk factor for development of PTSD to subsequent traumas. The association between previous exposure to traumatic experiences and posttraumatic stress disorder (PTSD) resulting from subsequent trauma has been reported $[19,36,37]$. Early life victimization in women who have been raped have been reported to have adverse effects on the likelihood and course of the psychological sequelae of the later trauma in the form of PTSD. Similar findings have been also shown in men fighting a subsequent war [38,39]. Further a history of childhood trauma as a risk for PTSD following adult trauma has been shown in a meta-analysis of 77 studies of risk factors for PTSD. This meta-analysis showed a positive correlation across populations regardless of gender, trauma type, or population studied [40]. Higher rates of childhood trauma have also been reported in Vietnam combat veterans with PTSD [36,37,41].

However the existing literature does not clearly establish the relation between childhood trauma and the subsequent development of PTSD. As Owens et al. has recently raised questions regarding the general presumption of negative effects of trauma in war veterans vis-a-vis early life traumas [42]. Similar observations were earlier argued by Stein et al. in [43]. This presumption needs to be evaluated further before any firm conclusions are drawn. The mechanisms by which early life trauma can present risk for adult PTSD need to be examined further.

\section{Neurobiological Effects}

Considerable interest was generated by early research on the physiologic effects of stress, leading to the idea that external events could have a profound impact on the biology and behavior of organisms.44 Catecholamines and glucocorticoids that are the first stage of defense to circumstances that threaten homeostasis (i.e. stress). An endocrine response to stress is activated when faced with provocative stimuli, exaggerated HPA activity or extended exposure to high glucocorticoid levels is also harmful to the developing brain $[45,46]$.

A prolonged traumatic stress response often results in abnormal timing, intensity, and pattern of catecholamine activity in a child's maturing brain [47]. It has been observed that there is an elevation in cortisol and catecholamines in maltreated children with PTSD compared with normal control subjects Further a blunted diurnal variation of cortisol has been seen among women with a reported history of childhood physical or sexual abuse $[48,49]$.

A similar blunted response has been also seen among adults with history of abuse or neglect in early life [21] Researchers have found that HPA axis dysregulation was uniquely associated with those abused children with high depressive or internalizing symptoms. Research also suggests that the HPA axis is more responsive to stress in symptomatic survivors of trauma, in PTSD [50].

Specific brain areas such as hippocampal volume might also be affected by prolonged over-stimulation of the HPA stress response system, also likely as a result of over secretion of CRF, which has been reported to exert toxic effects on hippocampal neurons [51]. Small hippocampal size has been seen in trauma survivors than those without traumatic experiences [52].

The basic mechanisms through which these traumas lead to these phenotypic changes has been the formation of gene products. This process in turn influence cellular processes that lead to gene expression, protein formation, and concomitant biological and behavioural change [53]. The stress based changed effects and the subsequent transmission could be reason for genetic or epigenetic basis for individual differences in stress reactivity [54]. The neurobiological impact of trauma is under active research.

\section{Resilience and Protective Factors}

Resilience is a dynamic process wherein individuals display positive adaptation despite experiences of significant adversity or trauma [55]. With regard to childhood traumas, resilience is a multifaceted amalgamation of genetic predispositions and personal, familial, and environmental risk and protective factors [56]. The literature 
is extensive, upholding the importance of protective psychological factors in the prevention of negative outcomes [57]. Children exposed to different kinds of trauma frequently show resilience in the form of protective characteristics that follow multiple pathways to foster their positive development $[55,58]$. However research so far has not been very clearly strict to delineate the risk factors and protective factors visa-vis the outcome of trauma [59].

Resilient maltreated children have been characterized as showing positive self-esteem, ego flexibility, and ego over control [60]. Environmental factors that possibly promote positive mental health despite traumatic experiences and protect against PTSD are social acknowledgement, social support, relationships and relationship quality, and stable living conditions during adolescence [61-64] other factors that promote better outcome, interpreted as components of the psychometric construct of resilience are humour and spirituality [65].

Positive features of families are associated with positive child adaptation following violence. Effective parenting has been one of the most well studied protective factors for early life traumas [66]. Religious and spiritual involvement and obedience to local clergy, Imams and spiritual healers foster psychometric construct of resilience. In addition, hope has been reported as an important variable in resilience $[67,68]$.

\section{Conclusion}

Childhood traumas have been shown to affect the physical, psychological and emotional well being. The long-term effect of childhood traumas seems to be linked with the development of depression, anxiety disorders, and personality disorders beyond PTSD, although the differences are seen based on the type of trauma. Re-victimization of adults with childhood traumatic experiences are prone to develop PTSD. Fostering humour and spirituality besides effective parenting and social support are protective in these traumas. Recognition of trauma-related stress in children is the first step towards healthier adulthood. The genetic and neurobiological evidence is not scarce to prove the effect of these traumas beyond doubt.

\section{Competing Interests}

The authors declare that they have no competing interest.

\section{References}

1. Kessler RC, Sonnega A, Bromet E, Hughes M, Christopher B, et al. (1995) Posttraumatic stress disorder in the National Co-morbidity Survey. Archives of General Psychiatry 52: 1048-1060.

2. Holmes R (1986) Acts of war. New York: Free Press.

3. Daly RJ (1983) Samuel Pepys and posttraumatic stress disorder. British Journal of Psychiatry 143: 64-68.

4. Khan AY, Margoob MA (2006) Paediatric PTSD: Clinical presentation, traumatic events and socio-demographic variables- experience from a chronic conflict situation; JK-Practitioner 13 (Suppl 1): S40-44.

5. Andrews G, Henderson S, Hall W (2001) Prevalence, comorbidity, disability and service utilization. $\mathrm{Br} \mathrm{J}$ Psychol 178: 145-153.

6. De Girolamo, Farlane A (1996) the epidemiology of PTSD: A comprehensive review of the international literature. Traumatic stress journal S78-84.

7. Friedman E, Gerrity R, Ethnocultural aspects of posttraumatic stress disorders: Issues, research and clinical applications (pp. 33-86). Washington DC: American Psychological Association.

8. DeJong J, Komproe IH, Van Ommeren M, El Masri M, Araya M, et al. (2001) Lifetime events and posttraumatic stress disorder in post-conflict settings. Journal of the American Medical Association 286: 555-562.

9. Heider D, Matschinger H, Bernert S, Alonso J, Brugha TS, et al. (2008) Adverse parenting as a risk factor in the occurrence of anxiety disorders : a study in six European countries. Soc Psychiatry Psychiatr Epidemiol 43: 266-272.

10. Gibb BE, Chelminski I, Zimmerman M (2007) Childhood emotional, physical and sexual abuse, and diagnoses of depressive and anxiety disorders in adult psychiatric outpatients. Depress Anxiety 24: 256-263.

11. A comprehensive textbook of psychiatry Kaplan HL, Sadock BJ; Williams and Wilkins Vol 2, (7thedn), 2000, p 2763.

12. Margoob MA, Majid A (2004) changing Sociodemographic pattern of substance abuse in Kashmir valley. JK Practitioner Jan Marvol II No 1: 14-16.

13. Newman CJ (1976) Children of disaster, clinical observations at Buffalo Creak. Am J Psychiatry 138: 306-312.

14. Kingston W, Rosser R (1974) Disaster: effects on physical and mental state. J Psychosom Res 18: 437-456.

15. Quarantelli EL, Dynes RR (1977) Response to social crisis and disasters. Annual Review of Sociology 3: 23-49.

16. Taylor V (1977) Good news about disaster. Psychology Today, October, p93) (Tierney KJ, Baisden B: Crises Intervention Programs for Disaster Victims: A Source Book and Manual for Smaller Communities. DHEW Publication (ADM) 79-675. Washington DC, US Government printing office, 1979.

17. Murray B (2007) What Is Childhood Trauma? Journal Watch Psychiatry July.

18. American Professional Society on the Abuse of Children. Guidelines for Psychosocial Evaluation of Suspected Psychological Maltreatment in Children and Adolescents. Chicago, IL: American Professional Society on the Abuse of Children; 1995.

19. Bremner JD, Southwick SM, Johnson DR, Yehuda R, Charney DS (1993) Childhood physical abuse and combat-related posttraumatic stress disorder in Vietnam veterans. Am J Psychiatry 150: 235-239.

20. Lang AJ, Aarons GA, Gearity J, Laffaye C, Satz L, et al. (2008) Direct and indirect links between childhood maltreatment, posttraumatic stress disorder and women's health. Behav Med 3: 125-135.

21. Van der Vegt EJ, Tieman W, van der Ende J, Ferdinand RF, Verhulst FC, et al. (2009) Impact of childhood adversities on adult psychiatric disorders: A study of international adoptees. Soc Psychiatry Psychiatr Epidemiol 44: 724-731.

22. Klein DN, Arnow BA, Barkin JL, Dowling F, Kocsis JH, et al. (2009) Early adversity in chronic depression: Clinical correlates and response to pharmacotherapy. Depression Anxiety 26: 701-710.

23. Dutra L, Bureau JF, Holmes B, Lyubchik A, Lyons-Ruth (2009) Quality of early care and childhood trauma: A prospective study of developmental pathways to dissociation. J Nerv Ment Dis 197: 383-390.

24. Greenfield EA, Marks NF (2009) Profiles of physical and psychological violence in childhood as a risk factor for poorer adult health: Evidence from the 19952005 National Survey of Midlife in the United States. J Aging Health 21 943-966.

25. Afifi TO, Enns MW, Cox BJ, de Graaf R, ten Have M, et al. (2007) Child abuse and health-related quality of life in adulthood. J Nerv Ment Dis 195: 797-804.

26. Finkelhor D, Ormrod RK,Turner HA (2007) Poly-victimization: A neglected component in child victimization. Child Abuse \& Neglect 31: 7-26.

27. Catani C, Schauer E, Elbert T, Missmahl I, Bette JP, et al. (2009) War trauma, child labor, and family violence: Life adversities and PTSD in a sample of school children in Kabul. J Traumatic Stress 22: 163-171.

28. Klasen F, Daniels J, Oettingen G, Post M, Hoyer C, Adam H (2010) Posttraumatic resilience in former Ugandan child soldiers. Child Developmen 81: 1096-1113.

29. Neugebauer R, Fisher PW, Turner JB, Yamabe S, Sarsfield JA, et al. (2009) Post-traumatic stress reactions among Rwandan children and adolescents in the early aftermath of genocide. Int J Epidemiol 38: 1033-1045.

30. John PB, Russell S, Russell PS (2007) The prevalence of posttraumatic stress disorder among children and adolescents affected by tsunami disaster in Tamil Nadu. Disaster Manag Response 5: 3-8.

31. McDermott BM, Lee EM, Judd M, Gibbon P (2005) Posttraumatic stress disorder and general psychopathology in children and adolescents following a wildfire disaster. Can J Psychiatry 50: 137-143.

32. Shaw JA, Applegate B, Tanner S, Perez D, Rothe E, et al. (1995) Psychological 
effects of Hurricane Andrew on an elementary school population. J Am Acad Child Adolesc Psychiatry 34: 1185-1192.

33. Horowitz K, Weine S, Jekel J (1995) PTSD symptoms in urban adolescent girls: Compounded community trauma. J Am Acad Child Adolesc Psychiatry 34: 1353-136.

34. Schwarz ED, Kowalski JM (1991) malignant memories: PTSD in children and adults after a school shooting. J Am Acad Child Adolesc Psychiatry 30: 936-944.

35. Pratchett LC, Yehuda R (2011) Foundations of posttraumatic stress disorder: does early life trauma lead to adult posttraumatic stress disorder? Dev Psychopathol 23: 477-491.

36. Davidson JRT, Hughes D, Blazer DG (1991) Post-traumatic stress disorder in the community: an epidemiological study. Psychol Med 21: 713-721.

37. Zaidi LY, Foy DW (1994) Childhood abuse experiences and combat-related PTSD. J Trauma Stress 7: 33-42.

38. Foa EB, Riggs DS (1993) Posttraumatic stress disorder and rape, in American Psychiatric Press Review of Psychiatry, vol 12. Edited by Oldham JM, Riba MB, Tasman A. Washington, DC, American Psychiatric Press pp 273-303.

39. Solomon Z, Mikulincer M, Jakob BR (1987) Exposure to recurrent combat stress: combat stress reactions among Israeli soldiers in the Lebanon war. Psychol Med 17: 433-440.

40. Brewi CR, Andrews B, Valentine JD (2000) Meta-analysis of risk factors for posttraumatic stress disorder in trauma-exposed adults. J Consult Clin Psychol 68: 748-766.

41. Kulka RA, Schlenger WE, Fairbank JA, Hough RL, Jordan BK, et al. (1990) Trauma and the Vietnam War Generation: Report of Findings From the National Vietnam Veterans Readjustment Study. New York, Brunner/Mazel.

42. Owens GP, Dashevsky B, Chard KM, Mohamed S, Haji U, et al. (2009) The relationship between childhood trauma, combat exposure, and posttraumatic stress disorder in male veterans. Military Psychology 21: 114-125.

43. Stein AL, Tran GQ, Lund LM, Haji U, Dashevsky BA, et al. (2005) Correlates for posttraumatic stress disorder in GulfWar veterans: A retrospective study of main and moderating effects. J Anxiety Disord 19: 861-876.

44. Cannon WB (1914) the emergency function of adrenal medulla in pain and major emotions. American Journal of Physiology 33: 356-372

45. Meaney MJ, Bhatnagar S, Larocque S, McCormick CM, Shanks N, Sharma $\mathrm{S}$, Smythe J, Viau V, Plotsky PM. Early environment and the development of individual difference in the hypothalamic-pituitary-adrenal stress response. In Pfeffer, C. (ed.), Severe Stress \& Mental Disturbance in Children, American Psychiatric Press, Washington, DC 1996.

46. Perry BD, Pollard R, Blakley T, Baker W, Vigilante D (1995) Childhood trauma, the neurobiology of adaptation, and "use-dependent" development of the brain: How "states" become "traits." Infant Men. Health J 16: 271-291.

47. Perry BC (2009) Childhood experience and the expression of genetic potential: What childhood neglect tells us about nature and nurture. Brain Mind 3: 79-100.

48. Brewer-Smyth K, Burgess AW (2008) Childhood sexual abuse by a family member, salivary cortisol, and homicidal behavior of female prison inmates. Nurs Res 57: 166-174.

49. Weissbecker I, Floyd A, Dedert E, Salmon P, Sephton S (2006) Childhood trauma and diurnal cortisol disruption in fibromyalgia syndrome. Psychoneuroendocrinology 31: 312-324.

50. Yehuda R, Teicher MH, Trestman RL, Levengood RA, Siever LJ (1996) Cortisol regulation in posttraumatic stress disorder and major depression: $A$ chronobiological analysis. Biol Psychiatry 40: 79-88.

51. Brunson KL, Eghbal-Ahmadi M, Bender R, Chen Y, Baram TZ (2001) Longterm, progressive hippocampal cell loss and dysfunction induced by early-life administration of corticotropin-releasing hormone reproduce the effects of early-life stress. Proc Natl Acad Sci USA 98: 8856-8861.
52. Margoob M, Malik YA, Bashir W, Jehangir M, Yaqoob M, et al. (2006) A Preliminary MRI Study of Hippocampal Volume in Chronic Posttraumatic Stress Disorder. JK-Practitioner 13 (Suppl 1): S66-S68.

53. Hyman SE, Nestler EJ (1996) Initiation and adaptation: A paradigm for understanding psychotropic drug action. Am J Psychiatry 153: 151-162.

54. Yehuda R, Bierer LM, Schmeidler J, Aferiat DH, Breslau I, et al. (2000) Low cortisol and risk for PTSD in adult offspring of Holocaust survivors. Am J Psychiatry 157: 1252-1259.

55. Luthar SS, Cicchetti D, Becker B (2000) the construct of resilience: A critical evaluation and guidelines for future work. Child Dev 71: 543-562.

56. Rutter M (1999) Resilience concepts and findings: Implications for family therapy. Journal of Family Therapy 21: 119-144.

57. Taylor SE, Kemeny ME, Reed GM, Bower JE, Gruenewald TL (2000) Psychological resources, positive illusions, and health. Am Psychol 55: 99-109.

58. Masten AS (2000) Ordinary magic: Resilience processes in development. Am Psychol 56: 227-238.

59. Kraemer HC, Kazdin AE, Offord DR, Kessler RC, Jensen PS, et al. (1997) Coming to terms with the terms of risk. Arch Gen Psychiatry 54: 337-343.

60. Cicchetti D, Rogosch FA (1997) The role of self-organization in the promotion of resilience in maltreated children. Dev Psychopathol 5: 629-647.

61. Jones B, Müller J, Maercker A (2006) Trauma and posttraumatic reactions in German development aid workers: prevalences and relationship to socia acknowledgement. Int J Soc Psychiatry 52: 91-100.

62. Maercker A, Müller J (2004) Social acknowledgment as a victim or survivor: a scale to measure a recovery factor of PTSD. J Trauma Stress 17: 345-351.

63. Ozer EJ, Best SR, Lipsey TL, Weiss DS (2003) Predictors of posttraumatic stress disorder and symptoms in adults: a meta-analysis. Psychol Bull 129: $52-73$

64. Collishaw S, Pickles A, Messer J, Rutter M, Shearer C, et al. (2007) Resilience to adult psychopathology following childhood maltreatment: evidence from a community sample. Child Abuse Negl 31: 211-229.

65. Connor KM (2007) Assessment of resilience in the aftermath of trauma. J Clin Psychiatry X 67(Suppl 2): 46-49.

66. Levendosky AA, Huth-Bocks AC, Shapiro DL, Semel MA (2003) The impact of domestic violence on the maternal-child relationship and preschool-age children's functioning. J Fam Psychol 17: 275-287.

67. Huda M, Margoob MA (2006) Pir, Faqir and psychotherapist: their role in psychosocial intervention of trauma. JK Pract 13: S89-93.

68. Santa Barbara J (2000) The psychological effect of war on children. In: Levy BS, Sidel VW (eds): War and Public Health. Washington, DC: Oxford University Press 168-185. 